Literature Reviews

\title{
Retrofitting the Electric Lighting and Daylighting Systems to Reduce Energy Use in Buildings: A Literature Review
}

\author{
${ }^{1}$ Marie-Claude Dubois, ${ }^{2}$ Fabio Bisegna, ${ }^{1}$ Niko Gentile, \\ ${ }^{3}$ Martine Knoop, ${ }^{4}$ Barbara Matusiak, ${ }^{5}$ Werner Osterhaus and ${ }^{6}$ Eino Tetri \\ ${ }^{I}$ Division of Energy and Building Design, Institute for Architecture and the Built Environment, \\ Lund University, Lund, Sweden, Box 118, 22100 Lund, Sweden \\ ${ }^{2}$ Department of Astronautical Electrical and Energetic Engineering, \\ Faculty of Engineering, SAPIENZA University of Rome, Via Eudossiana 18-00184, Rome, Italy \\ ${ }^{3}$ Technische Universität Berlin, Einsteinufer 19, 10587 Berlin, Germany \\ ${ }^{4}$ Faculty of Architecture, NTNU Norwegian University of Science and Technology, \\ Alfred Getz vei 3, 7491 Trondheim, Norway \\ ${ }^{5}$ Department of Engineering, Lighting Research Design Laboratory, Aarhus University, \\ Dalgas Avenue 2, DK-8000 Aarhus C, Denmark \\ ${ }^{6}$ Aalto University, PO Box 13340, 00076 Aalto, Finland
}

Article history

Received: 05-07-2015

Revised: $10-07-2015$

Accepted: 28-07-2015

Corresponding Author: Marie-Claude Dubois Division of Energy and Building Design, Institute for Architecture and the Built Environment, Lund University, Lund, Sweden, Box 118, 221 00 Lund, Sweden

E-mail: marie-claude.dubois@ebd.lth.se
Abstract: This paper presents a literature review about energy-efficient retrofit of electric lighting and daylighting systems in buildings. The review, which covers around 160 research articles, addresses the following themes: (1) retrofitting electric lighting in buildings, (2) electric lighting energy use and saving potential and (3) lighting retrofit strategies. The retrofit strategies covered in the review are: replacement of lamp, ballast or luminaire; use of task-ambient lighting design; improvement in maintenance; reduction of maintained illuminance levels; improvement in spectral quality of light sources; improvement in occupant behavior; use of control systems; and use of daylighting systems. The review indicates that existing general knowledge about lighting retrofit is currently very limited and that there is a significant lack of information concerning the actual energy performance of lighting systems installed in the existing building stock. The resulting key directions for future research highlights issues for which a better understanding is required for the spread and development of lighting retrofit.

Keywords: Lighting Retrofit, Energy-Efficiency, Luminaires, Lamps, Lighting Controls, Daylighting Systems, Occupant Behavior

\section{Introduction}

Projections by the International Energy Agency (IEA, 2006) show that if governments only rely on current policies, global electricity use for lighting will grow to around $4250 \mathrm{TWh}$ by 2030 , an alarming increase of more than $40 \%$. Due to the world's growing population and the increasing demand for electrically driven services in emerging economies, this increase will occur despite constant improvements in energy efficiency of electric systems. Tsao and Waide (2010) claimed that there is a massive potential for growth in the consumption of light if new lighting technologies are developed with higher luminous efficacies and lower cost of light. Many authors (e.g. Porritt et al., 2013) have warned about this so-called rebound effect, which means that with the reduced system power in lighting-and fixed energy prices-the tendency is to use more light because it is cheaper and by that absolute energy consumption is ultimately increased. Increase in efficiency will thus not necessarily produce an absolute reduction of energy use, as observed by William Stanley Jevons in 1865 . The Jevons Paradox, which was first expressed in relation to use of coal, states that an increase in efficiency in using a resource leads to increased use of that resource rather than to a reduction (Polimeni et al., 2007). However, Saunders and Tsao (2012) argued that even in this scenario, the increase in efficiency should be pursued because it will at least lead to economic benefits.

To sum up: There is a high saving potential with new lighting technologies. High quality lighting can be 
achieved in energy-efficient and more sustainable ways with appropriate retrofits. However, awareness of possible rebound effects is important; therefore, actions to raise awareness, measures targeting absolute energy savings and understanding of the potential to improve lighting quality in existing buildings are all urgently needed. This article focuses on the available energy saving strategies in lighting or daylighting (façade and roofs) retrofit and their potential as described in the scientific literature.

\section{Lighting Offers Great Energy Saving Potential}

Lighting has been pointed out as one of the areas with significant improvement potential in energyefficiency. One study (Enkvist et al., 2007) pointed out that investment in energy-efficient lighting is one of the most cost-effective ways for improving energyefficiency in buildings and reduce $\mathrm{CO}_{2}$ emissions. According to Krarti et al. (2005), energy retrofits of lighting equipment are very cost-effective with typical payback periods of less than two years. In addition, higher costs of electricity compared to most other energy sources (e.g. natural gas) in most countries further justifies ranking lighting retrofit measures high on the list of options as suggested by Boyano et al. (2013). One report (AEFEETS, 2010) even stated that the cost of saving $1 \mathrm{kWh}$ lighting energy through efficiency is less than $20 \%$ of the average price of 1 $\mathrm{kWh}$ electricity in the United States.

In a recent article, Dubois and Blomsterberg (2011) presented key energy use figures and saving potential for electric lighting in office buildings based on a literature review. This review concluded that an annual energy intensity of $10 \mathrm{kWh} / \mathrm{m}^{2}$ is a realistic target for electric lighting in future low energy office buildings. According to these authors, this would yield a significant reduction in energy intensity of at least $50 \%$ compared to the actual average electricity use for office lighting. This review also discusses different strategies for reducing lighting energy use in addition to providing a summary of saving potential. Many of these strategies are further discussed and updated in the present article.

\section{Importance of Retrofitting the Existing Building Stock}

According to Zhenjun et al. (2012), retrofitting should be considered as one of the main approaches to achieving sustainability in the built environment at relatively low cost and high uptake rates. These authors point out that most energy is consumed by existing buildings and the replacement rate of existing buildings by the new-build is only around 1.0-3.0\% per annum (see also Eames et al., 2013; Itani et al., 2013 ) and it is $2.2 \%$ per year in the commercial building sector. Current renovation and refurbishment rates are somewhat higher-between $2.9 \%$ and $5 \%$ in the UK of existing stock for domestic buildings and 2$8 \%$ for commercial stock, depending on the sector (Stafford et al., 2011). In the UK, for instance, some $70 \%$ of total 2010 building stock is expected still to be in use in 2050 (BBP, 2010). Therefore, rapid improvement of energy efficiency in existing buildings is needed for a timely reduction in global energy use and promotion of environmental sustainability (Zhenjun et al., 2012).

During the last decade, many governments (e.g. USA, UK, Australia and others) and international organisations (e.g. IEA) have put significant efforts towards energy efficiency improvement in existing buildings (Zhenjun et al., 2012). For instance, the International Energy Agency (IEA) has launched a series of Annex projects (Annex 46, 50, 55, 56) to promote energy efficiency of existing buildings. In the field of lighting, the IEA launched Annex 45-Energy efficient electric lighting for buildings under the umbrella of the Energy Conservation in Buildings and Community Systems (ECBCS) programme. More recently, the IEA launched a new task within the Solar Heating and Cooling (SHC) Programme entitled 'IEA Task 50-Advanced Lighting Solutions for Retrofitting Buildings'. This article was prepared as part of the dissemination effort of this international Task, which will be completed at the end of 2015. Further information can be found at the Task website http://task50.iea-shc.org/.

\section{Objectives of this Literature Review}

This literature review was achieved with the aim to analyze and summarize existing information found in the scientific literature, previous European and international research projects, websites of national projects, etc. The specific objectives of this literature review are listed below:

- Identify existing databases of case studies

- Identify previous research about lighting and/or daylighting retrofit

- Update key information regarding energy saving strategies and solutions demonstrated in the past by research, monitoring or demonstration projects

- Summarize the energy saving potential according to measure or strategy

Table 1 summarizes some of the key ideas presented in the introduction as outlined by this literature review. 
Table 1. SWOT analysis of the lighting retrofit situation

\begin{tabular}{ll}
\hline Strengths & High demonstrated energy savings of new lighting technologies and control systems \\
& Demonstrated short payback times \\
& Minimal disruption of lighting retrofit compared to many other retrofit measures \\
Weaknesses & Lack of knowledge and hands-on experience about many retrofit measures in a retrofit \\
& context (reduced illuminance, task-ambient lighting design, improvement of spectral quality \\
& of light source, improved occupant behavior etc.) \\
& Uncertainty of predicted energy savings and lack of reliability of some control systems \\
(occupancy and daylight- linked)
\end{tabular}

\section{Method}

This review is based on information mainly found in peer-reviewed journal articles, conference articles, reports, past relevant IEA and European or national projects published during the last 20 years (i.e. in the period 1993-2013). The articles were identified by first performing a search in several databases (Science Direct, Compendex, Inspec, etc.) with the following keywords: lighting retrofit, energy-efficient lighting, relamping, luminaires, lamps, lighting control, light sensors, dimming, daylight retrofit, daylighting systems, etc. Subsequently, the bibliography of each article was scrutinized to find other relevant sources. The authors also asked all experts of IEA Task 50 for articles related to retrofitting and lighting. Finally, the main author registered for automatic email alerts in various fields in order to get updates on new relevant articles. This thorough process allowed finding over 350 publications of which about half were judged directly or indirectly relevant and further analyzed after reading the abstract. This article thus summarizes information found in some 160 research articles on lighting and/or daylighting retrofit.

\section{Main Findings}

\section{Retrofitting Electric Lighting in Buildings}

Generally, previous research (Dascalaki and Santamouris, 2002; Erhorn-Kluttig et al., 2004) suggested that it is necessary to look at energy saving measures in a holistic way since electric lighting reductions normally entail an increase in heating demand, which can make lighting retrofit measures less cost effective considering all other end-uses. For example, Zmeureanu and Peragine (1999) investigated by computer simulations the net energy impact of lighting system retrofit taking into account the interactions with HVAC systems for an existing, 28floor, $100000 \mathrm{~m}^{2}$ office building from 1983 built in Montreal, Canada. Overall, the results indicated that the net energy savings were about $70 \%$ of the gross lighting energy savings for most cases of recessed fluorescent fixtures, due to an increase in heating demand. They argued that the improvement of the lighting system might thus be less cost effective than expected initially when only considering the gross energy savings by the lighting system alone.

Hestnes and Kofoed (2002) suggested that improvements in lighting should be combined with building envelope improvements to avoid the related increase in heating loads. However, they argued that since electricity is usually more expensive than thermal energy, any saving in electricity use is a more valuable improvement. In addition to this, when heating is provided by a heating system (instead of a lighting system), it is targeted, controllable, more effective and does provide better thermal comfort. Electric lighting systems are not designed to provide thermal comfort and they are generally not effective at heating in a building. Finally, it is also worth mentioning that a reduction in lighting energy use also yields a reduction of internal heat gains and thus cooling needs are reduced while summertime thermal comfort is generally improved.

\section{Electric Lighting Energy use and Saving Potential}

Lighting consumes $15-60 \%$ of the final energy use in buildings according to Spyropoulos and Balaras (2011), a wide variation, which depends on many factors such as building type, function, technology used, climate, etc. Previous research suggests that the potential for energy savings depends significantly on the initial energy demand for lighting and on the building type. Higher initial lighting load and more compact building shapes generally present higher saving potential since these cases generally have higher electric lighting demand compared to other installations and building types (Dascalaki and Santamouris, 2002). Note that daylight provisions are also less likely to be sufficient in such buildings. 
One study (Chidiac et al., 2011) demonstrated that reductions in energy use were not necessarily a linear addition of the savings from individual Energy Retrofit Measures (ERMs). For example, the implementation of light dimming features with more efficient lighting fixtures is not as effective in reducing consumption as a linear addition would indicate. Generally, the overall reduction in energy consumption is less than the linear addition of the individual ERMs.

\section{Lighting Retrofit Strategies}

\section{Lamp, Ballast and Luminaire Replacement}

Studies about energy-efficient lighting retrofit generally suggest that most existing lighting installations consist of fluorescent lighting (with conventional ballasts). One American study (Baker, 2013) stated that the most commonly retrofitted fixtures (in the USA) are the 4-lamp T12 while parabolic and lenses troffers with $\mathrm{T} 12$ or older T8 lamps are the primary lamp types to replace. This study also outlined that energy savings are generally decreasing over time, due to increases in new construction baselines and decreases in the number of existing very inefficient lighting systems ('low-hanging fruit').

According to another American author (Vogel, 2012), specifiers have four traditional options to consider in lighting retrofit:

1. Relamp and reballast

2. Delamp and reballast

3. One-for-one fixture replacement

4. Complete redesign

Options 3 and 4 represent a higher investment since entry into the plenum is required-a key factor affecting the cost of retrofitting-but they also present a higher saving potential. A new generation of lighting retrofit kits is available in energy efficient LED options. According to Vogel (2012), these kits enable component parts to be installed in $15 \mathrm{~min}$ or less into the housing of old fixtures, provide better quality and better looking fixtures and involve minimal disruption because they are installed below the ceiling.

\section{Retrofits with LED Lamps}

The hottest topic in lighting today is probably the possible replacement of different lamp types by highly efficient LED lamps. Rapid developments in the area of Solid-State Lighting (SSL) technology have created a real reorganization of the lighting industry worldwide with great emphasis on enormous potential savings. An analysis of LED retrofit lamps offered on the market (as alternative and equivalent to linear fluorescent solutions) carried out as part of IEA Task 50 Subtask B indicated that these lamps have a reduced energy consumption (approximately 50\%), a life time typically two to three times higher, a comparable color rendering and a beam angle of around $140^{\circ}$.

Labayrade and Avouac (2013) recently evaluated the performance of 10000 samples of a customized LED solution, which were optimized to replace low voltage halogen lamps ( $4 \mathrm{~W}$ equivalent to a $20 \mathrm{~W}$ halogen and a $5,5 \mathrm{~W}$ equivalent to a $35 \mathrm{~W}$ halogen lamp). A total of 9300 retrofits were evaluated in uncontrolled environments (restaurants, cafes and shops), in which more than $85 \%$ of the users were satisfied with the light produced by the LED spots and would consider replacing their halogen lamps with it.

However, the CALIPER study in the USA (U.S. Department of Energy, 2010) investigated 14 LED retrofit downlights that were equivalent to typical $\mathrm{CFL}$ downlights $(32 \mathrm{~W})$ and incandescent downlights (65 $\mathrm{W})$, which are typically applied for ambient lighting in normal ceiling heights. This study indicated that the luminous flux was too low for all tested 'MR16 equivalent' LED retrofit solutions, having a product efficacy of 16-35 $\mathrm{lm} / \mathrm{W}$. Color rendering ranged from 61 to 96 and color temperature was not near the target CCT or Planckian locus. This study also pointed out that the low wattage lamps might not provide enough load to the existing transformer, dimmers or related controls. In that case, the retrofits may not work or cause flicker or stroboscopic effects. However, note that this study is already six years old, a period with much development in SSL technology.

A more recent study (Poplawski and Miller, 2013) nevertheless showed that a wide variation in flicker performance and unfamiliar flicker characteristics can still be found amongst LED lighting solutions (also in Lehman et al., 2011; U.S. Department of Energy, 2010). Their study was based on the evaluation of 22 traditional lighting technology sources (incandescent, halogen, metal halide and fluorescent lamps) and 93 LED products (mainly retrofit lamps). Since flicker can affect well-being and performance, it seems to be a relevant quality criterion to take into consideration in the choice of LED retrofit solutions. The IES (2010) recommends a minimum driver output frequency of $120 \mathrm{~Hz}$ to avoid perceptible flicker, but the analysis by Poplawski and Miller (2013) indicates that this is insufficient to ensure quality. As no standard procedure for evaluation of flicker is currently available (CIE, 2013; Lehman et al., 2011), Poplawski and Miller (2013) proposed a light source evaluation using a flicker frequency dependent maximum flicker index. Another author (Osterhaus, 2014) stressed the need for appropriate combinations of LED sources and LED drivers. Inappropriate combinations can lead to flicker problems, which motivates the need to test sources and drivers as a unit, not as two separate components. 
In addition, a study performed by $\mathrm{NC}$ (2012) indicated that LED lamps and equivalent compact fluorescent lamps have comparable average life-cycle energy consumption (approximately 3,900 MJ per 20 million lumen-hours). For the purpose of the analysis, a LED lamp luminous efficacy of $641 \mathrm{~m} / \mathrm{W}$ was used. But as the efficacy of LED lamps increases, the lifecycle energy consumption will diminish, since the energy consumption in use represents the significant portion of the total life-cycle energy consumption (approximately 90 percent).

Earlier, Ryckaert et al. (2011) evaluated 12 different brands of LED retrofit lamps as alternative for a linear fluorescent solution (T8/36W, 3500-4000 K, $3350 \mathrm{~lm}$ ). They assessed the quality of the retrofit lamps through laboratory measurements at the beginning of the project and after $2000 \mathrm{~h}$. The lamp efficacy of the LED retrofit was between $50,8 \mathrm{~lm} / \mathrm{W}$ and $89,5 \mathrm{~lm} / \mathrm{W}$, compared to 75 and $95 \mathrm{~lm} / \mathrm{W}$ for the linear fluorescent solution, depending on the ballast chosen. The majority of the retrofits had a CRI below 80 and would therefore not be suitable for office applications. Lumen depreciation over $2000 \mathrm{~h}$ varied from $-38,7 \%$ to $+7,1 \%$ amongst the different brands. In addition to the product evaluation, the application of three selected retrofits was studied in a small office room. The authors concluded that, at that time, replacing T8 fluorescent lamps with 'equivalent' LED retrofits would indeed bring energy savings up to $70 \%$, but would reduce at the same time the illuminance levels by about $50 \%$, which is consistent with findings from a recent field study (Osterhaus, 2014). The latter was noticed by nearly all of the 44 subjects that evaluated the lighting conditions in the small office room. In addition to this major limitation, they noted that the luminous intensity distribution of the luminaire with all three retrofits changed considerably, which affected the illuminance distribution and uniformity as well as the impression of the room.

In summary, despite the promising savings that LED retrofits may bring in the future, many serious issues such as flicker, low illuminance levels, poor beam distribution and color rendering have been reported and should be given serious consideration in real retrofit projects.

\section{Retrofits with T8 and T5 Lamps}

In the context of Malaysia, Mahlia et al. (2011) investigated the potential energy savings, Life Cycle Cost (LCC) and payback period of the lighting system in the campus buildings of the University of Malaya, by using theoretical calculations and standard cost and payback equations. They compared retrofitting the existing standard fluorescent lighting systems (T12) with T8 magnetic (18/36W), T8 electronic $(18 / 36 \mathrm{~W})$, HPT8 electronic $(17 / 32 \mathrm{~W})$ and T5 electronic $(14 / 28 \mathrm{~W})$ ballasts. According to these authors, T8 lamps can replace the old T12 fluorescent lamps without any modification of the fixture while the use of T5 system requires electronic ballasts with high efficiency version that can reach a lamp luminous efficacy superior to $100 \mathrm{~lm} / \mathrm{W}$. However, the reader should consider that replacement to T5 tubes might require more controlled luminaire outputs (e.g. more louvers or baffles) to prevent glare due to the higher luminance of the light source, thus perhaps reducing efficacy. According to these authors, T5 lamps can last at least $18,000 \mathrm{~h}$ with $5 \%$ reduction of lumen output in the lifetime. In contrast, a T8 light tube usually lasts about $20,000 \mathrm{~h}$ but it loses about $20 \%$ output in its life. Mahlia et al. (2011) found that using T8 electronic system, HPT8 system and T5 lamps with electronic ballasts could reduce the energy consumption and LCC by $17 \%, 31 \%$ and $40 \%$ respectively at $100 \%$ retrofitting. Assuming an increase in electricity tariff of $2 \%$ per year, they also found that if retrofitting was fully done $(100 \%)$, the payback period for T8 electronic would only be 0.689 years while it would be 1.24 years for HPT 8 and 1.95 years for $\mathrm{T} 5$ electronic alternative.

Table 2 summarizes the potential energy savings reported with replacement of lighting technology.

\section{Task-Ambient Lighting Design}

Use of task-ambient lighting design has proven to provide better quality lighting and a $22-25 \%$ reduction in electricity use compared to a standard general energyefficient lighting installation, as discussed by Dubois and Blomsterberg (2011). However, no study has been found here about task-ambient lighting design approach in a retrofit context. This strategy certainly needs to be studied in a retrofit context.

\section{Improvement in Maintenance}

According to Hanselaer et al. (2007), a high maintenance factor (cleaning) together with an effective maintenance programme promotes energy efficient design and limits the installed lighting power requirements.

Gasparovsky and Raditschova (2013) studied the luminous properties of old type luminaires after decades of their operation. They measured their efficacy in their actual conditions and after cleaning, with inserted and reference lamps. The measurements included luminous flux, luminous efficiency (in integrating sphere), luminous intensity distribution curve (with goniophotometer), spectral transmittance of diffuser in order to assess the yellowish effect of UV radiation (using a spectrophotometer) and electrical characteristics of the lamp-ballast system. They concluded that luminaires from the 1980s have significant non-recoverable losses of about $10 \%$ in case of interior luminaires. Pollutants (e.g. dust) collecting on the surfaces of the luminaire are responsible for another 10$20 \%$ reduction in performance, but these can be recovered through cleaning. The luminous efficacy of old-type T12 fluorescent lamps is $15 \%$ lower than catalogue values but in comparison with recent technology their efficacy was only half. 
Table 2. Potential energy savings by using more energy-efficient lighting technology in retrofit projects

\begin{tabular}{llll}
\hline Technology & Potential energy savings & Issues & Source \\
\hline Linear fluorescent ${ }^{\mathrm{a}}$ to LED & $50 \%$ & $\begin{array}{l}\text { Flicker, reduced illuminance, } \\
\text { poor beam distribution and color rendering }\end{array}$ & IEA Task 50 \\
T8 to LED & $70 \%$ & & Ryckaert et al. (2011) \\
T12 to T8 & $17 \%$ & & Mahlia et al. (2011) \\
T12 to HPT8 & $31 \%$ & & \\
T12 to T5 & $40 \%$ & & \\
\hline
\end{tabular}

a unspecified

b electronic

Mucklejohn et al. (2013) reported on fundamental basics of lighting design and the dimensioning of lighting taking the specific factors and aspects of light conversion and delivery into account. They presented case studies for a warehouse area $(70 \mathrm{~m} \times 54 \mathrm{~m})$ without any windows or skylights. In six configurations, HIDMH (High-intensity discharge metal halide) luminaires were compared with High Efficiency Plasma (HEP) light sources. Under the same maintenance conditions, they claimed that HEP light sources can fulfil the lighting design requirements with a total installed power of $22 \mathrm{~kW}$ while the design with HID-MH light sources requires $38.6 \mathrm{~kW}$. Assumptions on the cleaning interval, e.g. extending the cleaning interval from 1 to 3 years led to an increase of $9.5 \%$ in the installed power in order to always guarantee the required light levels. Changes in the reflectances and their impact were demonstrated by changing the wall reflectance from $50 \%$ to $10 \%$. For the HID-MH configuration for instance this again asked for a design with more fittings and therefore an increased installed power by $4.8 \%$ compared to the base case.

\section{Reduction of Maintained Illuminance Levels}

Boyce et al. (2006) claimed that lighting practice that uses $500 \mathrm{~lx}$ as the target for maintained illuminance is excessive. According to these authors, by using $400 \mathrm{~lx}$ as a design criterion, a $20 \%$ decrease in energy consumption could be gained together with a likely increase in the percentage of office workers who are within $100 \mathrm{~lx}$ of their preferred illuminance.

No study was found where the issue of reduced illuminance level was specifically addressed in a retrofit context. However, Baker (2013) discussed trends in new construction and retrofit lighting projects as seen in four years of energy efficiency incentive programs in Texas, USA and reported that in most cases, the number of lamps was reduced, which is partly due to the 'education around proper light level as many facilities are currently over-lit'.

Indeed, many studies (e.g. Galasiu et al., 2007; Boyce et al., 2006; Moore et al., 2002; 2001; Veitch and Newsham, 2000; Newsham et al., 2008) have indicated that office workers generally prefer illuminance levels that are lower than recommended by the standards particularly if they work with a computer most of the time (Escuyer and Fontoynont, 2001). For example, a Canadian study (Veitch and Newsham, 2000) conducted in an open-plan office laboratory where forty-seven matched pairs of participants spent a day completing various simulated office tasks and questionnaires showed that individually preferred light levels varied widely (mean desktop illuminance 423 lx, s.d. 152 lx, min. 83 lx, max $7251 x$ ), but on average required $10-15 \%$ less power than prevailing energy code recommendations. Another study (Schuler, 1995) in a computer hardware and software distribution company, where each of the offices contained at least two computers, showed through measurements that most employees felt comfortable with a lighting level of around 100 lux (as opposed to the standard regulations of workplaces demanding 300 to 500 lux at desk level). Meanwhile, a French field study (Escuyer and Fontoynont, 2001) involving worker interviews in three office buildings, distinguished between two distinct groups: a small group spending more than $70 \%$ of their time working on the computer, for which light levels were low (100-300 lux) and a bigger group spending less than $70 \%$ of their time working on the computer for which light levels were higher (300-600 lx). These results are in line with those of an earlier French study by Berrutto et al. (1997).

However, in a more recent Finnish study by Viitanen et al. (2013), lighting quality parameters were studied in an office lighting setting for three different luminaire types: (1) square LED panel luminaire (Sq_LED); (2) round LED downlight luminaire (Ro_LED); and (3) rectangular recessed T5 fluorescent lamp luminaire (Re_T5). Re_T5 lighting was compared to Sq_LED lighting at 300, 600 and 1000 1x. Ro_LED lighting was studied at three different color temperatures: 3000,4500 and $6000 \mathrm{~K}$. The subjects evaluated $600 \mathrm{~lx}$ to be equally pleasant to $1000 \mathrm{~lx}$ and the reading task was evaluated to be equally easy at these two illuminance levels. However, 1000 lx caused slightly more glare and 300 $\mathrm{lx}$ was considered to be less pleasant. Visual performance regarding reading and detail distinction on the wall was more difficult at $300 \mathrm{~lx}$ than at higher illuminance levels. At $600 \mathrm{~lx}$, the amount of light was considered to be more optimal than at 300 or $1000 \mathrm{~lx}$. When the users adjusted illuminance, the overall 
average preferred illuminance was $648 \mathrm{~lx}$ for Re_T5 lighting and $517 \mathrm{~lx}$ for the LED lighting; but the authors noted that there were large variations in the preferred illuminances between subjects.

Finally, it might be worthwhile pointing out the potential impact of vertical illumination, rather than just horizontal illuminance: if vertical surfaces appear welllit, lower horizontal illuminance values might be tolerated more easily.

\section{Improvement in Spectral Quality of Light Sources}

Better match between the lighting system's spectral qualities and the user's visual response can provide an optimal, energy-efficient lighting solution. Rea et al. (2009) have shown, for instance, that they could achieve energy savings (of the order of $37 \%$ according to Rea, 2010) in outdoor lighting applications by using Metal Halide (MH) lamps instead of the more common HighPressure Sodium (HPS) since MH spectra are better tuned to the spectral sensitivity of the human retina at mesopic light levels. Note that the illuminance ratio between an MH and an HPS light source has been measured to be about 0.7 for equivalent brightness perception in the high end of the mesopic luminance range $\left(>0.1 \mathrm{~cd} / \mathrm{m}^{2}\right)$ (Rea, 1996; Fotios and Cheal, 2007). The same logic can be applied to indoor lighting situations. Rea (2010) indicated, for instance, that at the same brightness level, $6500 \mathrm{~K}$ T8 fluorescent lamps use $35 \%$ less energy than $3000 \mathrm{~K} \mathrm{~T} 8$ fluorescent lamps.

A recent field study (Osterhaus, 2014) carried out at Horsens Hall in Denmark, where $2700 \mathrm{~K}$ fluorescent lamps were retrofitted with $6000 \mathrm{~K}$ LED panels, indicated that the $6000 \mathrm{~K}$ lamps were judged to be brighter than the $2700 \mathrm{~K}$ source despite the fact that they provided slightly lower illuminance values on the work surface. Although this retrofit case involved two different types of light sources, it still suggests that the spectral light distribution of the light source is very critical in terms of subjective brightness perception.

\section{Occupant Behavior}

Masoso and Grobler (2010) claimed that 'behavioural change has energy saving potential comparable and in most cases higher than that of technological solutions'. The most salient feature of behavioural change is that it is largely no cost, it needs no hi-tech knowledge, it is readily applicable to both new and existing buildings, it is largely appreciated by many (though not practiced) and it has a self-perpetuating potential in that once occupants of a building have developed an energy conservation culture, they spread it to their new comers as well as take it with them to other places. It might even be worthwhile addressing the need for good user manuals for buildings and their systems. When occupants know how the systems are designed and how they are supposed to operate and when they know how to get short-comings of a system rectified, they will be less likely to disable systems and become more aware of the energy-saving mentality. Manuals should also explain the purpose of the light energy saving technology or control system.

Unfortunately, only a few studies have been found addressing the energy saving potential related to occupant behavior or evaluating the consequences for human performance, health and well-being of energysaving lighting strategies in a retrofit context.

One study (Mahdavi et al., 2008) analyzed occupants' operation of lighting and shading systems by monitoring three office buildings from nine months to a year. They found that the probability of switching the light on upon arrival increased significantly when the horizontal illuminance at the proximity of the workstation was less than $200 \mathrm{~lx}$. The same authors also obtained a probability model for switching the lights off as a function of the duration of absence from the offices.

Another study (Coleman et al., 2013) demonstrated that an installed wireless system was found to help individuals evaluate their energy-related behaviors and identify personal actions that are not apparent from aggregated building-level feedback. Neither study provides clear data about the potential energy savings achievable through improved occupant behavior.

Table 3 provides a summary of the potential energy savings achievable with the lighting retrofit strategies discussed in the last five sections of this literature review.

\section{Use of Control Systems}

The use of electric lighting control systems-in order to provide light exactly at the right time, to the right level and in the right place - can significantly contribute to reduce the consumption of electricity for lighting. Recently, Boyano et al. (2013) presented key energy use figures and explored the energy saving potential in office buildings across Europe by simulating (with Energy Plus) several currently available Energy Conservation Measures (ECMs) for three representative locations across Europe (cold, mild and warm climate). With partial daylight-linked dimming control (on 50\% of office building facilities), they obtained a potential energy saving between 9 and $37 \%$ of the total energy consumed and 18 to $37 \%$ with total lighting control (100\% of office building facilities).

Earlier, Fostervold et al. (2010) investigated the potential for energy savings and possible consequences for the workers by implementing new luminaires and a new lighting control system in a large hospital building. They obtained reductions in lighting energy use by 55 $75 \%$ (depending on the control system) with neither positive nor negative effect on individual well-being and concentration or negative outcomes of adaptive lighting systems due to reduced degree of perceived control. 
Table 3. Potential energy savings by using specific lighting retrofit strategies

\begin{tabular}{llll}
\hline & Potential energy savings & Retrofit studies & Source \\
\hline Task-ambient & $22-25 \%$ & No & Dubois and Blomsterberg (2011) \\
Improved maintenance & $5-20 \%^{\mathrm{a}}$ & Yes & Gasparovsky and Raditschova (2013) \\
& & & Mucklejohn et al. (2013) \\
Reduced maintained illuminance & $20 \% \mathrm{o}^{\mathrm{b}}$ & No & Boyce et al. (2006) \\
Improved spectral quality of light source & $35 \% \mathrm{c}^{\mathrm{c}}$ & No & Rea (2010) \\
Improved occupant behavior & $\mathrm{n} / \mathrm{a}$ & No & Mahdavi et al. (2008) Coleman et al. (2013) \\
\hline
\end{tabular}

a light loss if no maintenance program is applied

b from 500 to 400 lux

c for a specific lighting technology

Prior to this, Granderson and Agogino (2006) developed an intelligent lighting dimming system in order to balance user comfort, energy savings and retrofit costs using an influence diagram approach. This system utilizes wireless sensing and actuation technology to relieve much of the expense associated with retrofitting. In contrast to traditional systems that use a single ceiling-mounted photosensor per control zone, the intelligent system uses Smart Dust motes placed directly on each work surface. Illuminance sensing is performed with photodiodes embedded on the motes, while occupancy sensing is accomplished with mote accelerometers fixed to occupants' chairs, or with commercial personal occupancy sensors. Validation and fusion algorithms are used to mitigate interference from the users. Smart dust motes offer significantly reduced retrofit costs since they are wireless and directly interfaced with ballasts. They avoid the need to access power lines behind the walls and ceiling of an office. The authors (Granderson and Agogino, 2006) tested this system by simulation and found that replacing the existing non-dimming system designed under previous Illuminating Engineering Society (IES) guidelines with a commercial dimming system would generate $13 \%$ energy savings and a $15 \%$ cost savings. On the other hand, the intelligent system increased the energy savings to $26 \%$ and the cost savings to $20 \%$.

In general, the saving potential varies greatly according to context and building: different studies show different energy savings, which leads to difficulties in calculating the payback time of a lighting retrofit action. Williams et al. (2012) tried to overcome this difficulty through a meta-analysis based on the review of 88 scientific papers and reports which included the potential savings from lighting control systems. The authors categorized the different strategies and listed the study typology as well as the key features of each document. Applying increasing restrictive filters, they concluded that there is a potential saving of $24-38 \%$ for different lighting control systems in actual installation. The study also pointed out that the simulations generally overestimate the savings compared to field studies. The effect, in this case, is higher when the lighting control system has a higher level of automation and/or technology, such as daylight harvesting technologies.
The authors also found that there is a consistent effect of the switch-off delay in the occupancy strategies.

It might be worthwhile pointing out that Simpson (2003) claimed that office buildings are probably the most important application for lighting control systems, but also an application where individuals will likely have strong opinions about lighting control. While systems might have been installed with the best of intentions, he states that some 'have been unsuccessful to the extent that users have disconnected the automatic element or even the entire lighting control system'. He argues that specifiers of lighting control systems need to be aware of various factors when selecting a lighting control system:

- People behave differently when lighting is under central control

- People of different ages and visual abilities have different requirements and even those with the same age and ability might have different preferences

- Occupancy times of spaces vary widely, especially for private office and other work spaces

- Unpredictability of lighting system behaviour is generally disliked

- Very quick and very large changes in illuminance levels are difficult to handle for the human eye

- The extent of daylight contributing to the workplace illumination typically varies significantly with the distance to windows

- The orientation of the workspace's daylight openings can result in highly seasonal or diurnal problems affecting the users

- The introduction of blinds and other shading devices affects the way in which automated lighting control systems work

- Appropriate placement of light and/or presence sensors is crucial for achieving user satisfaction and energy savings

- The type of occupancy of the space is a considerable 'human' factor

\section{Manual Controls}

Manual control systems, such as door switches, manual task lamps and manual dimmers, can offer an unexpectedly high saving potential. For example, a 
survey conducted in France (IEA, 2006) reported energy savings of up to $77 \%$ by installing more manual switches in open plan offices. Besides energy savings, the possibility of controlling the light environment has a positive effect on the users' mood according to Moore et al. (2002), which is also related to monetary savings. Juslén et al. (2007) have shown an increase of $4,5 \%$ in productivity in a factory hall where manually dimmable task lights were provided to the workers.

In an earlier study carried out in the USA (Jennings et al., 2000), five different lighting control scenarios were tested in an office building located in San Francisco. Among these scenarios, two considered the use of manual controls. In the first case, a bi-level switching gave the possibility to choose to turn on only a part of the light fixtures. In the second scenario, the electric lighting was turning on automatically when people were entering the offices, but it could be manually dimmed afterwards. The bi-level switching offered about $23 \%$ energy savings compared with a classic switch, while the second scenario (automatic on with dimming) provided about $26 \%$ energy savings. Nevertheless, the authors analysed the behaviour of the users and found quite important differences in individual preferences. For example, in the bi-level switching case, about $63 \%$ of the occupants used mostly the full-light setting, $13 \%$ used mainly $2 / 3$ of the light fixtures and the remaining used mostly $1 / 3$ of the light fixtures.

In general, the saving potential is not predictable because it largely depends on individual behaviours according to Boyce et al. (2000). In small office rooms, the occupants tend to adjust the light level, which leads to both a more pleasant lighting environment and energy savings (see also Love, 1998; Gentile et al., 2013). In open space offices, a strategy could be to provide manually adjustable task lighting, while keeping some automatic controls for the general electric lighting.

Recently, a solution that combined automation with individual preferences was proposed by Wen and Agogino (2011). They proposed a lighting design method enabling dynamic, personalized and optimal horizontal illumination of open-plan offices by using an elaborated control mechanism to tune each lamp in the office according to each occupant's preference and need. The prototype lighting system was tested in an open-plan office. The overall energy savings for the year analyzed was 51\% compared to the original all on/off lighting configuration.

\section{Occupancy Controls}

One of the most effective approaches to minimize energy use in the non-residential sectors is by using occupancy based lighting control systems (IEA, 2006; Garg and Bansal, 2000; Galasiu et al., 2007). As a result of occupants not turning the lights off when they no longer need them, more energy is spent on non-working hours than during scheduled time according to a study by Masoso and Grobler (2010).
A recent article by Motta Cabrera and Zareipour (2013) presented an experimental research aiming to quantify and understand lighting energy waste patterns in a post-secondary educational institute located in Calgary, Canada. They collected data over a full academic year in three typical classrooms. Data association mining was used in order to extract association rules and explore lighting waste patterns. They made an energy assessment to account for the amount of energy, money and $\mathrm{CO}_{2}$ emissions spent by each classroom throughout the year and obtained energy wastes of $126.4 \mathrm{kWh} / \mathrm{seat}, \quad 49.2 \mathrm{kWh} / \mathrm{seat}$ and $62.8 \mathrm{kWh} /$ seat respectively for the three classrooms. The average number of waste instances for all three classrooms was $44.24 \%$, which means that the lights were turned on with no one in the classroom for $10.6 \mathrm{~h}$ in an average day. They finally demonstrated by simulation that if the waste patterns were avoided, significant savings, up to $70 \%$ of the current energy use, could be achieved.

Another recent article (Itani et al., 2013) concerned the effect of Energy Conservation Measures (ECMs) for an existing eight-storey building located in Beirut, Lebanon. The authors analysed the impact of low investment and minimal disruption ECMs that can maintain thermal comfort and good indoor air quality. The ECMs were Investigated by using a commercial energy analysis software (IES-VE) and varying the indoor temperature cooling set point, lighting control, etc. They used a standard system audit methodology and advanced energy modelling techniques to replicate the existing building base case. The lighting energy use in the building studied used less percentage of total energy compared to most ordinary office buildings due to the use of efficient lights (T5 and CFLs with an average LPD of $10.23 \mathrm{~W} / \mathrm{m}^{2}$ ) and the large daylighting available from the glazed façade. Substantial energy savings were achieved by implementing scheduled lighting controls and by placing occupancy sensors in meeting rooms and private offices. The schedule of lighting was also adjusted by turning off some lights during unoccupied and low occupancy hours, which yielded reductions in the lighting energy corresponding to $11.8 \%$ savings in lighting energy or a $2.6 \%$ saving in overall building energy consumption due to a simultaneous decrease in lighting and cooling loads. The economic analysis showed that lighting control and increasing temperature set point are two ECMs that should be implemented because of short payback period of $1.3 \pm 0.2$ years, respectively.

According to Motta Cabrera and Zareipour (2013), one obstacle of implementing an occupancy-based lighting-control is the uncertainty on the amount of energy that could be saved. Previous research papers report differences in expected savings, typically ranging from 25\% to 75\% (Garg and Bansal, 2000; Moore et al., 2003; Richman et al., 1995; Granderson and Agogino, 2006). This could be due to the fact that each space has a 
different occupancy profile based on the schedules and activities of people in the building (see e.g. Guo et al., 2010; Rubinstein et al., 2003).

In addition to this, the switching strategy seems to play a significant role. The occupancy control system could automatically turn on/off the electric lighting when the presence is detected (presence switches), or only switch off a manually turned on system when any movement is recognized (absence switches). The differences in savings between these two approaches could be high, especially in individual or small offices, as shown by Gentile et al. (2012). These authors showed that using a presence (on/off) control system in small offices would yield higher energy use for lighting than a simple manual switch at the door with an absence detector (switch off), confirming results from previous research (Voss et al., 2006).

In an earlier study (Garg and Bansal, 2000), it was found that by optimizing the time delay, energy savings from using an occupancy sensor increased from $20 \%$ to $25 \%$. In an earlier study in eight buildings (Richman et al., 1995), which included conference rooms, mail room, restrooms, one training room and laboratory areas, it was found that occupancy sensors had the potential to save between $24 \%$ and $79 \%$ of energy consumption by using a 10-min time delay. When the time delay was decreased to a 2-min setting, the potential savings range increased to $76-93 \%$, with negative impact on user comfort.

Guo et al. (2010) presented a review of occupancybased lighting control systems where they analyzed the typologies of sensors generally used for this kind of lighting control systems, as well as the settings generally applied during the installation. Regarding the sensors, while several technologies are available, the market often offers only PIR (Passive Infrared), ultrasonic or hybrid PIR/ultrasonic presence sensors, which are offering a good compromise between feasibility, accuracy and costs. Each of these systems presents some limitation regarding the position of the sensor, the room area, the geometry, etc. This makes the savings conditioned by proper installation and post-installation commissioning. Guo et al. (2010) concluded that a cheap and feasible solution could be to have a network of sensors rather than a single expensive one. With focus on the settings, this review shows that the savings with 20 min of delay could be as high as $46 \%$, while it grows up to $86 \%$ when delay is reduced to $5 \mathrm{~min}$.

As mentioned previously, shorter time delays for the switch-off reduce the energy consumption, but could be unacceptable for the occupants. The general recommendation is to keep 10-20 min time delay, never accepting shorter time delays than $7 \mathrm{~min}$. Note also that the effectiveness of those systems is largely dependent on the pattern of use of the space. Generally, irregularly occupied spaces offer higher saving potential.

\section{Daylight-Linked Control Systems}

Several studies have indicated that daylighting can provide a cost-effective alternative to electrical lighting for commercial and institutional buildings (Ihm et al., 2009). In addition, it is generally acknowledged that daylight is preferred to electric light, fosters higher productivity and performance (Plympton et al., 2000; Säter, 2010). According to many authors, simulation studies as well as field monitoring, daylighting controls can result in significant lighting savings ranging from 30 to 77\% (Doulos et al., 2008; Li et al., 2006; Lee and Selkowitz, 2006; Onaygil and Guler, 2003; Ihm et al., 2009; Kobav and Bizjak, 2010). However, previous surveys have indicated that daylighting control strategies are not commonly integrated in buildings ( $\mathrm{Li}$ and Lam, 2003). According to Ihm et al. (2009) and Krarti et al. (2005), this may be explained by the lack of simplified prediction tools.

A recent field study (Chow et al., 2013) considered a corridor space adjacent to a large skylight atrium. The combination of high daylight availability and low illuminance requirements for corridor spaces, suggested the use of daylight-linked control system with efficient T5 light fixtures. The solution led to an overall energy saving of $93 \%$ compared to the existing lighting installation. The payback period for the proposed solution was calculated to be 3.42 years.

Another study achieved in Hong Kong (Li et al., 2006) investigated a fully air conditioned side-lighted open plan office with an initial power density for lighting of $16.7 \mathrm{~W} / \mathrm{m}^{2}$. The original two rows of fluorescent lamps closer to the window were improved by adding new high frequency ballasts and a photo sensor for daylight harvesting. A single photo sensor served all the upgraded fixtures. The authors obtained average energy savings of $33 \%$ compared to the nondimmable fixtures, with better performances during the central part of the day and the summer months.

In the Canadian climate, Galasiu et al. (2004) tested different combinations of lighting and shading control systems. For the electric lighting, the authors used dimmable and on/off daylight systems, which were combined with photo controlled blinds as well as with different cases of static positions of the blinds. The best case scenario offered possible energy savings of $50-60 \%$ with windows without blinds, which dropped by $5-80 \%$ with different static (predefined blind positions, not automatically controlled) window blinds settings.

An Italian study (Gugliermetti and Bisegna, 2005) performed in the Mediterranean area investigated the luminous and energy aspects related to the integration of control systems with different Electro Chromic (EC) and double glazed systems equipped with motorized internal shading devices. On/off and linear control strategies were used to change the transparency of EC systems 
from clear to dark state and to close the indoor curtains, while dimming and on/off strategies for managing the electric lighting. The study showed the significant impact of highly flexible controls of both electric and natural light also in climates where overheating and visual comfort problems are of great importance owing to the high level of daylight. They found that the difference in lighting electric power demand can be largely affected by the variation in the number of dimming zones. And still more important are the different situations obtained by changing the daylighting control: a finer regulation, such as that obtained by the linear control, involves a more uniform and continuous, but lighter, presence of electric lights with respect to simpler and less flexible regulation. This has been proved for both internal curtain control and ECs, from both energy efficiency and visual comfort points of view.

In an earlier study in a sub-tropical environment (To et al., 2002) considered a side-lit classroom with two rows of fluorescent tubes parallel to the windows. The closest row to the windows was replaced with a high frequency electronic daylight linked dimming system. In addition, the general horizontal illuminance was reduced from about 1000 lux to around 800 lux. The authors extrapolated the potential annual savings using a 16weeks data collection period, which demonstrated savings of the order of $40 \%$ compared to the full-power scenario. Considering the actual installation costs, the energy savings led to a payback period of 4.9 years for the tested installation, with projection of possible reduction up to 2.2 years for larger spaces.

Koyle and Papamichael (2010) installed an innovative dual-loop photo sensor control system in a $150000 \mathrm{ft}^{2}$ retail store. The system received readings from both open- and closed-loop sensors. It combined the information through an algorithm and determined the relative requested electric light output. Over a 12-month observation period, the authors found that the system was able to match the requested light levels $63.7 \%$ of the time and saved $36.6 \%$ energy compared to a retail store without daylight harvesting strategy. The payback time of this installation was determined to be 2.4 years.

In addition to the uncertainty in predicting the energy saving potential, several studies reported difficulties in real installation of daylight-linked dimming systems (e.g. Lee and Selkowitz, 2006; Gentile et al., 2012). The practical difficulties regard mainly the performance of the photo sensor (Ehrlich et al., 2002), since the whole system is based on its reading of the light environment. Frequent light switching under unstable sky conditions may compromise the savings ( $\mathrm{Li}$ et al., 2010). In addition, difficulties in matching the illuminance design levels because of overestimated number of light fixtures, changes in the space purpose (Choi and Sung, 2000) or actual occupancy rate of the space (Roisin et al., 2008) are also factors that may compromise the efficiency of the systems. A lack of awareness by the designers about the comprehensive performance of the real installations has also been identified (Ehrlich et al., 2002). Gentile et al. (2013) also pointed out the need for training installers to calibrate these systems properly or simply to be trained about the calibration settings of the systems they install.

Table 4 summarizes the findings regarding potential energy savings using lighting control systems.

\section{Use of Daylighting Systems}

Building facades and roofs, by their glass area ratio, shading or daylighting systems, may greatly affect electricity use for lighting, provided of course that electric lighting is switched off in the presence of daylight. Many studies report results related to daylight utilisation i.e. the replacement of electric light by daylight.

Sanati and Utzinger (2013) examined the effect of an interior light shelf system fixed in the upper part of windows on occupants' use of blinds in the lower part and on the consumption of electric lighting. The results suggest that in otherwise identical environmental conditions, occupants working in the 'light shelf zone' demonstrated a lower window occlusion than those located in the area with conventional windows. Light shelves distributed daylight more evenly, consequently, occupants in the 'light shelf zone' used less electric lighting.

Previously, daylighting systems have been developed to enhance daylight penetration or utilization. A large number of daylighting systems were evaluated within IEA Task 21 'Daylight in Buildings' (IEA, 2000) based on their ability to block or redirect daylight. Depending on the geographical location and its predominant daylighting conditions different daylighting systems seem to be suitable. Energy savings for electric lighting can be achieved with (angular) selective systems, such as anidolic solar blinds, using direct sunlight without glare, which is of specific relevance for mild and sunny climates. Sunlight-redirecting daylighting systems positioned in the upper part of the window plane, such as laser-cut-panels and prismatic panels, present energy saving potential as well, but need consideration with respect to position and angle to avoid glare. These systems are typically applied in sunny climates according to Edmonds and Greenup (2002), even though the laser-cut panel has shown its applicability in temperate climates as well (IEA, 2000). Other, more invasive, light redirecting systems, like light shelves and anidolic systems, redirect both diffuse and sunlight. Both can increase daylight penetration, but might reduce the sun-and daylight contribution near the façade. They have limited application in high-latitude countries, because of the additionally required shading device for a prevalent time of the year. The most efficient daylighting systems for moderate climates seem to be automatically controlled blinds and louvres, because of their flexibility to respond to different daylighting conditions. 
Table 4. Potential energy savings by using different types of lighting control systems

\begin{tabular}{|c|c|c|c|}
\hline & Potential energy savings & Retrofit studies & Source \\
\hline Manual controls & $23-77 \%$ & Yes & IEA (2006); Jennings et al. (2000) \\
\hline Scheduling & $12 \%$ & No & Itani et al. (2013) \\
\hline Occupancy control & $20-93 \%{ }^{\mathrm{a}}$ & Yes & $\begin{array}{l}\text { Motta Cabrera and Zareipour (2013); Garg and Bansal (2000); } \\
\text { Moore et al. (2003); Richman et al. (1995); Guo et al. (2010) }\end{array}$ \\
\hline $\begin{array}{l}\text { Daylight-linked } \\
\text { dimming }\end{array}$ & $10-93 \%$ & Yes & $\begin{array}{l}\text { Boyano et al. (2013); Doulos et al. (2008); Li et al. (2006); } \\
\text { Lee and Selkowitz (2006); Onaygil and Guler (2003); } \\
\text { Ihm et al. (2009); Kobav and Bizjak (2010); } \\
\text { Chow et al. (2013); Li et al. (2006); To et al. (2002); } \\
\text { Koyle and Papamichael (2010) }\end{array}$ \\
\hline $\begin{array}{l}\text { Combined daylight } \\
\text {-linked and occupancy }\end{array}$ & $26 \%$ & No & Granderson and Agonino (2006) \\
\hline
\end{tabular}

a Highly dependent on space occupancy and time delay

Ehling (2000) investigated the energy savings potential and economical aspects of daylighting systems under moderate climate conditions and concluded the pay back times for daylighting systems are typically extensive therefore also pleading for simple, cost effective, daylighting systems, such as blinds and louvres. These systems perform well under predominant sunny sky conditions as well.

A recent literature review (Nair et al., 2013) concluded that active systems, with for example sun tracking mirrors or lenses, can optimally collect daylight and with this offer high energy saving potential. Nonetheless, they are typically complex and relatively expensive and require regular maintenance. Passive systems have a poorer performance, but are typically cheap, simple and require less maintenance. Positive attributes of a good daylighting enhancement system are said to be passiveness, ease of installation, visual acceptance, solar shading against direct radiation and well-controlled output distribution.

\section{Conclusion}

As part of the international research 'IEA-Task 50Advanced Lighting Solutions for Retrofitting Buildings', this literature review pursued the aim to analyze information found in the scientific literature, previous international, European and national research projects in order to summarize the state of knowledge on lighting and daylighting retrofit.

Key conclusions that should be remembered from this literature review are stated below:

\section{General}

- Electric lighting is one of the major sources of electricity consumption in buildings representing 15$60 \%$ of the final energy use. It has a high saving potential at a reasonable pay-back period, especially due to the development of new lighting technologies with higher luminous efficacies and lower cost of light

- Reported energy savings through lighting retrofit vary widely depending on initial energy use, building type, usage, etc
- The so-called rebound effect may create a tendency to use more light because it is cheaper and by that absolute consumption could be ultimately increased.

- Energy savings measures should be considered in a holistic way since electric lighting reductions normally entail an increase in heating demand. Improvements in lighting should be planned along with building envelope improvements to compensate for the related increase in heating loads

Reductions in energy use are not necessarily a linear addition of the savings from individual Energy Retrofit Measures (ERMs). The overall reduction in energy consumption is generally less than the linear addition of the individual ERMs With respect to lighting retrofit strategies, the literature review shows the following

\section{Electric Lighting}

- $\quad$ Replacement of lamp, ballast and luminaire appears as the most often reported lighting retrofit strategy, with a great saving potential. The most common existing lighting installations consist of fluorescent lighting (with conventional ballasts) and most commonly retrofitted fixtures are the 4-lamp T12 and parabolic and lenses troffers with T12 or older T8 lamps (data from the USA)

- Compared to fluorescent lighting, LED lamps have reduced energy consumption (approximately 50\%) and a longer life time. Although good products are available, lighting quality aspects such as unsatisfactory color rendering, low light load, flicker and poor light distribution have been reported and need to be considered seriously to ensure user satisfaction

- Reducing the maintained illuminance level is another promising strategy since previous research indicated lower preferred illuminance levels compared to those recommended by the standards particularly in areas where computers are used. There are indications of a tendency to reduce the number of lamps (by 'delamping') partly due to the education around proper light levels and the fact that many facilities are currently overlit 
- Use of task-ambient lighting design has proven to provide better quality lighting and a 22-25\% reduction in electricity use compared to a standard general energy-efficient lighting installation but no study has been found about task-ambient lighting design approach in a retrofit context

\section{Occupant Behavior}

- Occupant behavior offers substantial energy saving potential but this strategy has not been sufficiently explored in retrofit context

\section{Lighting Control}

- The use of electric lighting control systems can also significantly reduce the consumption of electric lighting but the saving potential varies greatly according to context and building, which leads to difficulties in estimating the payback time of a lighting retrofit

- Simulations generally overestimate the savings compared to field studies; especially when the control system involves advanced automation and/or technology, such as daylight harvesting technologies

- Manual control systems, such as door switches, manual task lamps and manual dimmers, can offer an unexpectedly high saving potential with increase in occupant satisfaction and productivity

- Occupancy based lighting control systems are also very promising with high expected savings (20-93\%)

- Irregularly occupied spaces offer higher saving potential

- Optimizing the time delay has a significant impact on the energy savings

- Using a presence (on/off) control system could yield higher energy use for lighting than a simple manual switch at the door combined with absence detection (switch off), especially in individual or small offices

- Daylight-linked control systems can result in significant lighting savings, but several studies reported difficulties in real installations and in estimating the payback period at the design stage

\section{Daylighting Systems}

- Building facades, by their glass area ratio, shading or daylighting systems, may greatly affect electricity use for lighting provided that electric lights are switched off in presence of sufficient daylight

- Payback times for daylighting systems are typically extensive while passive daylighting or shading systems have a poorer performance, but are typically cheap, simple and require less maintenance, leading to better payback times

This review discussed several strategies for reducing electricity use in lighting retrofit projects. The review was limited to the topic of energy efficiency but the reader should be reminded that retrofitting a lighting installation offers several advantages besides energy savings: improvement in lighting quality, occupant satisfaction and productivity, improved corporate image, energy security, etc. The review generally shows that studies of lighting retrofit in real context with monitored data are surprisingly rare and most of the existing studies target either lamp-ballast-luminaire replacement or implementation of advanced control systems. Monitoring studies where simple and robust retrofit strategies such as task-ambient lighting design, improved occupant behavior, improvement in the spectral quality of light sources, or even a simple reduction of maintained illuminance levels have not been reported extensively in the literature despite their promising saving potential. This review suggests that research efforts addressing these specific strategies should be emphasized in the context of retrofitting buildings.

One of the next tasks of IEA Task 50, Subtask D, will hopefully contribute to bridge this gap by providing measured data on a number of real retrofitted buildings. This will provide more knowledge in this area, which will pave the way for further developments and acceleration of the lighting and daylighting retrofit activities worldwide.

\section{Acknowledgement}

The authors thank Jan de Boer and Anna Hoier from the Fraunhofer Institute for Building Physics (Stuttgart) for reviewing the last version of this article and providing fruitful comments and discussion.

\section{Funding Information}

The authors thank their respective funding agencies for supporting their work as part of IEA Task 50:

- Swedish Energy Agency (Statens energimyndighet), Sweden

- $\quad$ Finnish RYM Indoor Environment Program, Finland (http://www.rym.fi/en/programs/indoorenvironment program/)

- The Research Council of Norway, Norway

- Bundesministerium für Wirtschaft und Technologie, Germany

\section{Author's Contributions}

Marie-Claude Dubois: The article was written, coordinated and edited by.

Niko Gentile: The section on control systems was written by.

Fabio Bisegna: Contributed with some reading notes.

Eino Tetri: Contributed to the section on occupant behavior. 
Barbara Matusiak: Mainly contributed to the section on daylighting systems.

Martine Knoop: The section about light technologies.

Werner Osterhaus: Provided contributions in different sections but mostly on control systems and by reviewing the final version.

\section{Ethics}

This article is original and contains unpublished material. The corresponding author confirms that all of the other authors have read and approved the manuscript and no ethical issues involved.

\section{References}

AEFEETS, 2010. Real Prospects for Energy Efficiency in the United States. 1st Edn., National Academies Press, ISBN-10: 0309156866, pp: 352.

Baker, S.C., 2013. A bright future: Market transformation in texas lighting efficiency incentive programs. Energy Eng., 110: 35-36.

Berrutto, V., M. Fontoynont and P. Avouac-Bastie, 1997. Importance of wall luminance on users' satisfaction: Pilot study on 73 office workers. Proceedings of the 8th European Lighting Conference, Amsterdam, The Netherlands.

BBP, 2010. Low carbon retrofit toolkit: A roadmap to success. London, UK Better Buildings Partnership.

Boyano, A., P. Hernandez and O. Wolf, 2013. Energy demands and potential savings in European office buildings: Case studies based on energy plus simulations. Energy Build., 65: 19-28.

DOI: 10.1016/j.enbuild.2013.05.039

Boyce, P.R., N.H. Eklund and S.N. Simpson, 2000. Individual lighting control: Task performance, mood and illuminance. J. Illuminating Eng. Society, 29: 299-311. DOI: 10.1080/00994480.2000.10748488

Boyce, P.R., J.A. Veitch, G.R. Newsham, C.C. Jones and J.M. Heerwagen et al., 2006. Occupant use of switching and dimming controls in offices. Lighting Res. Technol., 38: 358-378.

DOI: $10.1177 / 1477153506070994$

Chidiac, S.E., E. Catania, E. Morofsky and S. Foo, 2011. Effectiveness of single and multiple energy retrofit measures on the energy consumption of office buildings. Energy, 36: 5037-5052.

DOI: 10.1016/j.energy.2011.05.050

Choi, A.S. and M.K. Sung, 2000. Development of a daylight responsive dimming system and preliminary evaluation of system performance. Build. Environ., 35: 663-676. DOI: 10.1016/S0360-1323(99)00055-4

Chow, S.K., D.H. Li, E.W. Lee and J.C. Lam, 2013. Analysis and prediction of daylighting and energy performance in atrium spaces using daylight-linked lighting controls. Applied Energy, 112: 1016-1024. DOI: 10.1016/j.apenergy.2012.12.033
CIE, 2013. Review of lighting quality measures for interior lighting with LED lighting systems. Proceedings of the CIE Lighting Quality and Energy Efficiency Conference, Mar. 3-5, Central Bureau, Vienna, Austria.

Coleman, M.J., K.N. Irvine, M. Lemon and L. Shao, 2013. Promoting behaviour change through personalized energy feedback in offices. Build. Res. Inf., 41: 637-651.

DOI: $10.1080 / 09613218.2013 .808958$

Dascalaki, E. and M. Santamouris, 2002. On the potential of retrofitting scenarios for offices. Build. Environ., 37: 557-567. DOI: 10.1016/S0360-1323(02)00002-1

Doulos, L., A. Tsangrassoulis and F. Topalis, 2008. Quantifying energy savings in daylight responsive systems: The role of dimming electronic ballasts. Energy Build., 40: 36-50. DOI: 10.1016/j.enbuild.2007.01.019

Dubois, M.C. and Å. Blomsterberg, 2011. Energy saving potential and strategies for electric lighting in future North European, low energy office buildings: A literature review. Energy Build., 43: 2572-2582. DOI: $10.1016 /$ j.enbuild.2011.07.001

Eames, M., T. Dixon, T. May and M. Hunt, 2013. City futures: Exploring urban retrofit and sustainable transitions. Building Res. Inf., 41: 504-516. DOI: $10.1080 / 09613218.2013 .805063$

Edmonds, I.R. and P.J. Greenup, 2002. Daylighting in the tropics. Solar Energy, 73: 111-121. DOI: $10.1016 / \mathrm{S} 0038-092 \mathrm{X}(02) 00039-7$

Ehling, K., 2000. Tageslichtsysteme: Lichttechnische Bewertung und Wirtschaftlichkeit. 1st Edn., VDIVerlag, Berlin, ISBN-10: 318316504X, pp: 117.

Ehrlich, C., K. Papamichael, J. Lai and K. Revzan, 2002. A method for simulating the performance of photosensor-based lighting controls. Energy Build., 34: 883-889. DOI: $10.1016 / \mathrm{S} 0378-7788(02) 00064-6$

Enkvist, P.A., T. Nauclér and J. Rosander, 2007. A Cost Curve for Greenhouse Gas Reduction. 1st Edn., McKinsey Quarterly, pp: 1-7.

Erhorn-Kluttig, H., H. Erhorn and S. Wössner, 2004. Exemplary retrofit concepts in Europe: Energyefficient public buildings (results from IEA/EUprojects).

Escuyer, S. and M. Fontoynont, 2001. Lighting controls: A field study of office workers' reactions. Lighting Res. Technol., 33: 77-96. DOI: $10.1177 / 136578280103300202$

Fostervold, K.I., P.J. Larsen, E. Lillelien, T. Mjøs and M.O. Berg, 2010. Energy efficient lighting control systems: Consequences for lighting quality, environment, health and human factors. Proceedings of the CIE Lighting Quality and Energy Efficiency, (CLQ’ 10), Vienna, Austria, pp: 368-375. 
Fotios, S.A. and C. Cheal, 2007. Lighting for subsidiary streets: Investigation of lamps of different SPD, Part 2 - Brightness. Lighting Res. Technol., 29: 233-252. DOI: $10.1177 / 1477153507080805$

Galasiu, A.D., M.R. Atif and R.A. MacDonald, 2004. Impact of window blinds on daylight-linked dimming and automatic on/off lighting controls. Solar Energy, 76: 523-544. DOI: 10.1016/j.solener.2003.12.007

Galasiu, A.D., G.R. Newsham, C. Suvagau and D.M. Sander, 2007. Energy saving lighting control systems for open-plan offices: A field study. J. Illuminating Eng. Society North Am., 4: 7-29. DOI: 10.1582/LEUKOS.2007.04.01.001

Garg, V. and N. Bansal, 2000. Smart occupancy sensors to reduce energy consumption. Energy Buildings, 32: 81-87. DOI: 10.1016/S0378-7788(99)00040-7

Gasparovsky, D. and J. Raditschova, 2013. Lighting properties and efficiency of luminaires exceeding their lifetime. Proceedings of CIE Centenary Conference, Paris, France, pp. 317-326.

Gentile, N., H. Håkansson and M.C. Dubois, 2012. Lighting control systems in individual offices at high latitude: measurement of lighting conditions and electricity savings. Proceedings of the International Conference on Energy Efficiency in Commercial Buildings, (IEECB '12), Frankfurt, Germany, pp: 333-344

Gentile, N., T. Laike and M.C. Dubois, 2013. Lighting control systems in peripheral offices rooms at high latitude: Measurements of electricity savings and users' preferences. Energy Procedia, 57: 1987-1996. DOI: $10.1016 /$ j.egypro.2014.10.063

Granderson, J. and A. Agogino, 2006. Intelligent office lighting: Demand-responsive conditioning and increased user satisfaction. J. Illuminating Engineering Society North Am. J. Illuminating Eng. Society North Am., 2: 185-198.

Gugliermetti, F. and F. Bisegna, 2005. A model study of light control systems operating with Electrochromic Windows. Lighting Res. Technol., 37: 3-20. DOI: $10.1191 / 13657828051$ li123oa

Guo, X., D.K. Tiller, G.P. Henze and C.E. Waters, 2010. The performance of occupancy-based lighting control systems: A review. Lighting Res. Technol., 42: 415-431. DOI: $10.1177 / 1477153510376225$

Hanselaer, P., C. Lootens, W.R. Ryckaert, G. Deconinck and P. Rombauts, 2007. Power density targets for efficient lighting of interior task areas. Lighting Res. Technol., 39: 171-184. DOI: $10.1177 / 1365782807076737$

Hestnes, A.G. and N.U. Kofoed, 2002. Effective retrofitting scenarios for energy efficiency and comfort: Results of the design and evaluation activities within the office project. Building Environ., 37: 569-574. DOI: $10.1016 / \mathrm{S} 0360-1323(02) 00003-3$
IEA, 2000. Daylight in Buildings: A Source Book on Daylighting Systems and Components. A Report of IEA SHC Task 21, ECBCS Annex 29. 1st Edn., International Energy Agency, Washington.

IEA, 2006. Light's Labour's Lost: Policies for EnergyEfficient Lighting. 1st Edn., OECD/IEA, Paris, pp: 558.

Ihm, P., A. Nemri and M. Krarti, 2009. Estimation of lighting energy savings from daylighting. Build. Environ., 44: 509-514.

DOI: $10.1016 /$ j.buildenv.2008.04.016

Itani, T., N. Ghaddar and K. Ghali, 2013. Strategies for reducing energy consumption in existing office buildings. Int. J. Sustainable Energy, 32: 259-275. DOI: $10.1080 / 14786451.2011 .622765$

Jennings, J.D., F.M. Rubinstein, D. DiBartolomeo and S.L. Blanc, 2000. Comparison of control options in private offices in an advanced lighting controls testbed submitted to the offices. Illuminating Eng. Society, 29: 39-60. DOI: 10.1080/00994480.2000.10748316

Juslén, H., M. Wouters and A. Tenner, 2007. The influence of controllable task-lighting on productivity: A field study in a factory. Applied Ergonomics, 38: 39-44. DOI: 10.1016/j.apergo.2006.01.005

Kobav, M.B. and G. Bizjak, 2010. Long term study: Energy savings obtained with use of daylight sensor and dimming ballasts. Proceedings of the CIE Lighting Quality and Energy Efficiency, (CLQ' 10), Vienna, Austria, pp: 618-621.

Koyle, B. and K. Papamichael, 2010. Dual-loop photosensor control systems: Reliable, cost-effective lighting control for skylight applications. Proceedings of the ACEEE Summer Study on Energy Efficiency in Buildings, (ASSE' 10), Pacific Grove, California, pp: 157-166.

Krarti, M., P.M. Erickson and T.C. Hillman, 2005. A simplified method to estimate energy savings of artificial lighting use from daylighting. Build. Environ., 40: 747-754.

DOI: 10.1016/j.buildenv.2004.08.007

Labayrade, R. and P. Avouac, 2013. Visual quality assessment of LED spots in comparison to lowvoltage halogen spots. Proceedings of Centenary Conference, (CIE' 13), Paris, France, pp: 348-377.

Lee, E.S. and S.E. Selkowitz, 2006. The New York times headquarters daylighting mockup: Monitored performance of the daylighting control system. Energy Build., 38: 914-929. DOI: $10.1016 /$ j.enbuild.2006.03.019

Lehman, B., A.J. Wilkins, S.M. Berman, M.E. Poplawski and N.J. Miller, 2011. Proposing measures of flicker in the low frequencies for lighting applications. Proceedings of the Energy Conversion Congress and Exposition, Sept. 17-22, IEEE Xplore Press, Phoenix, pp: 2865-2872. DOI: 10.1109/ECCE.2011.6064154 
Li, D.H., K.L. Cheung, S.L. Wong and T.N. Lam, 2010. An analysis of energy-efficient light fittings and lighting controls. Applied Energy, 87: 558-567. DOI: 10.1016/j.apenergy.2009.07.002

Li, D.H., T.N. Lam and S.L. Wong, 2006. Lighting and energy performance for an office using high frequency dimming controls. Energy Conversion Manage., 47: 1133-1145.

DOI: 10.1016/j.enconman.2005.06.016

Li, D. and J. Lam, 2003. An investigation of daylighting performance and energy saving in daylit corridor. Energy Build., 35: 356-373.

DOI: $10.1016 / \mathrm{S} 0378-7788(02) 00107-\mathrm{X}$

Love, J., 1998. Manual switching patterns in private offices. Lighting Res. Technol., 30: 45-50. DOI: $10.1177 / 096032719803000107$

Mahdavi, A., A. Mohammadi, E. Kabir and L. Lambeva, 2008. Occupants' operation of lighting and shading systems in office buildings. J. Build. Performance Simulation, 1: 57-65. DOI: $10.1080 / 19401490801906502$

Mahlia, T., H. Abdul Razak and M. Nursahida, 2011. Life cycle cost analysis and payback period of lighting retrofit at the University of Malaya. Renewable Sustainable Energy Rev., 15: 1125-1132. DOI: $10.1016 /$ j.rser.2010.10.014

Masoso, O. and L. Grobler, 2010. The dark side of occupants behaviour on building energy use. Energy Build., 42: 173-177.

DOI: 10.1016/j.enbuild.2009.08.009

Moore, T., D.J. Carter and A.I. Slater, 2001. A comparative study of user opinion in offices with and without individually controlled lighting. Proceedings of the 9th European Lighting Conference Lux Europa, (ELC' 01), Reykjavik, Iceland.

Moore, T., D.J. Carter and A.I. Slater, 2002. User attitudes toward occupant controlled office lighting. Lighting Res. Technol., 34: 207-219.

DOI: $10.1191 / 13657828021$ t048oa

Moore, T., D.J. Carter and A.I. Slater, 2003. Long-term patterns of use of occupant controlled office lighting. Lighting Res. Technol., 35: 43-57.

DOI: $10.1191 / 14771535031$ i061oa

Motta Cabrera, D.F. and H. Zareipour, 2013. Data association mining for identifying lighting energy waste patterns in educational institutes. Energy Buildi., 62 : 210-216. DOI : 10.1016/j.enbuild.2013.02.049

Mucklejohn, S.A., A.L. Whittaker and J. Gore, 2013. Unrevealing efficacy, maintenance and lighting energy for the end user. Proceedings of the CIE Centenary Conference, (CC' 13), Paris, France.

Nair, M.G., K. Ramamurthy and A.R. Ganesan, 2013. Classification of indoor daylight enhancement systems. Lighting Res. Technol., 46: 245-267.

DOI: $10.1177 / 1477153513483299$
NC, 2012. Life-cycle assessment of energy and environmental impacts of LED lighting products, part I: Review of the life-cycle energy consumption of incandescent, compact fluorescent and LED lamps. Department Energy.

Newsham, G.R., S. Mancini and R.G. Marchand, 2008. Detection and acceptance of demand-responsive lighting in offices with and without daylighting. LEUKOS: J. Illuminating Eng. Society North Am., 4: 139-156. DOI: 10.1582/LEUKOS.2007.004.03.001

Onaygil, S. and O. Guler, 2003. Determination of the energy saving by daylight responsive lighting control system with an example from Istanbul. Building Environ., 38: 973-977. DOI: 10.1016/S0360-1323(03)00034-9

Osterhaus, W., 2014. Daylight and electric light monitoring at horsens hall in denmark. Internal report IEA Task 50 Advanced Lighting Solution for Retrofitting Buildings.

Plympton, P., S. Conway and K. Epstein, 2000. Daylighting in schools: Improving student performance and health at a price schools can afford. National Renewable Energy Laboratory (NREL), Golden, Colorado.

Polimeni, J., K. Mayumi, M. Giampietro and B. Alcott, 2007. The Jevons Paradox and the Myth of Resource Efficiency Improvements. 1st Edn., Routhledge, ISBN-10: 1844074625, pp: 200.

Poplawski, M.E. and N.M. Miller, 2013. Flicker in solidstate lighting: Measurement techniques and proposed reporting and application criteria. Proceedings of the CIE Centenary Conference, (CC' 13), Paris, France.

Porritt, J., S. Tulej and S.A. Mucklejohn, 2013. The rebound effect-an overview of the implications for lighting energy. Proceedings of the CIE Centenary Conference, Paris, France.

Rea, M.S., 1996. Essay by invitation. Lighting Design Application, 26: 15-16.

Rea, M.S., 2010. Energy-efficient lighting. Energy efficient lighting in a human perspective. Proccedings of conference CEEBEL (Centrum för energieffektiv belysning), Katrineholm, Sweden.

Rea, M.S., J.D. Bullough and Y. Akashi, 2009. Several views of metal halide and high-pressure sodium lighting for outdoor applications. Lighting Res. Technol., 41: 297-320. DOI: $10.1177 / 1477153509102342$

Richman, E.E., A.L. Dittmer and J.M. Keller, 1995. Field analysis of occupancy sensor operation: Parameters affecting lighting energy savings. Illuminating Eng. Society North Am.

Roisin, B., M. Bodart, A. Deneyer and P. D'Herdt, 2008. Lighting energy savings in offices using different control systems and their real consumption. Energy Build., 40: 514-523.

DOI: $10.1016 / \mathrm{j}$. enbuild.2007.04.006 
Rubinstein, F., N. Colak, J. Jennings and D. Neils, 2003. Analyzing occupancy profiles from a lighting controls field study. Proceedings of CIE Session. San Diego, California.

Ryckaert, W.R., I.A. Roelants, M. van Gils, G. Durinck and S. Forment et al., 2011. Performance of LED linear replacement lamps. CIE, 2011. Proceedings of the 27th Session of the CIE. Sun City, South Africa.

Sanati, L. and M. Utzinger, 2013. The effect of window shading design on occupant use of blinds and electric lighting. Building Environ., 64: 67-76. DOI: 10.1016/j.buildenv.2013.02.013

Saunders, H.D. and J.Y. Tsao, 2012. Rebound effects for lighting. Energy Policy, 49: 477-478. DOI: 10.1016/j.enpol.2012.06.050

Schuler, M., 1995. Building simulation in application: Developing concepts for low energy buildings through co-operation between architects and engineer. Proceedings of the Solar World Congress, International Solar Energy Society (ISES), Harare, Zimbabwe.

Simpson, R., 2003. Lighting Control: Technology and Applications. Focal Press, Oxford.

ISBN-13: 978-0240515663.

Spyropoulos, G.N. and C.A. Balaras, 2011. Energy consumption and the potential of energy savings in Hellenic office buildings used as bank branches-A case study. Energy Build., 43: 770-778. DOI: 10.1016/j.enbuild.2010.12.015

Stafford, A., C. Gorse and L. Shao, 2011. The Retrofit Challenge: Delivering low carbon buildings. Centre for Low Carbon Futures, Leeds, UK.

Säter, M., 2010. Psychological, physiological and visual responses to electromagnetic radiation in natural and artificial light. Proceedings of CIE Lighting Quality and Energy Efficiency (LQEE' 10), Vienna, Austria, pp: 422-425.

To, D.W., L.K. Sing, T.M. Chung and C.S. Leung, 2002. Potential energy saving for a side-lit room using daylight-linked fluorescent lamp installations. Lighting Res. Technol., 34: 121-132. DOI: $10.1191 / 13657828021$ li038oa
Tsao, J.Y. and P. Waide, 2010. The world's apetite for light: Empirical data and trends spanning three centuries and six continents. LEUKOS: J. Illuminating Eng. Society North Am., 6: 259-281.

U.S. Department of Energy, 2010. DOE solid-state lighting caliper program. Summary of results: Round 11 of product Testing. Pacific Northwest National Laboratory.

Veitch, J.A. and G.R. Newsham, 2000. Preferred luminous conditions in open-plan offices: Research and practice recommendations. Lighting Res. Technol., 32: 199-212. DOI: $10.1177 / 096032710003200404$

Wen, Y.J. and A.M. Agogino, 2011. Personalized dynamic design of networked lighting for energyefficiency in open-plan offices. Energy Build., 43: 1919-1924. DOI: 10.1016/j.enbuild.2011.03.036

Viitanen, J., J. Lehtovaara, E. Tetri and L. Halonen, 2013. User preferences in office lighting: A case study comparing LED and T5 lighting. LEUKOS: J. Illuminating Eng. Society North Am., 9: 261-290.

Williams, A., B. Atkinson, K. Garbesi, E. Page and F. Rubinstein et al., 2012. Lighting controls in commercial buildings. J. Illuminating Eng. Society North Am., 8: 161-180.

Vogel, K., 2012. Strategies for lighting retrofits. LD+A, The magazine of the Illuminating Engineering.

Voss, K., G. Löhnert, S. Herkel, A. Wagner and M. Wambsganß, 2006. Bürogebäude mit Zukunft: Konzepte-Analysen-Erfahrungen. 2nd Edn., Solarpraxis, Berlin, Germany.

Zhenjun, M., P. Cooper, D. Daly and L. Ledo, 2012. Existing building retrofits: Methodology and state-of-the-art. Energy Buildi., 55: 889-902. DOI: $10.1016 /$ j.enbuild.2012.08.018

Zmeureanu, R. and C. Peragine, 1999. Evaluation of interactions between lighting and HVAC systems in a large commercial building. Energy Conversion Manage., 40: 1229-1236.

DOI: $10.1016 / \mathrm{S} 0196-8904(99) 00011-4$ 